\title{
Drug resistance-associated mutations in antiretroviral treatment-naïve and -experienced patients in Kuwait
}

\author{
W. CHEHADEH ${ }^{1}$, O. ALBAKSAMI², S. E. JOHN¹, W. AL-NAKIB ${ }^{1}$ \\ ${ }^{1}$ Department of Microbiology, Faculty of Medicine, Kuwait University, Kuwait; ${ }^{2}$ Infectious Diseases Hospital, \\ Ministry of Health, Kuwait
}

Received December 18, 2017; revised February 22, 2018; accepted July 3, 2018

\begin{abstract}
Summary. - The identification of human immunodeficiency virus (HIV) mutations leading to drug resistance enables patient-specific adaptation of the treatment regimen and predicts the risk of transmission of drugresistant HIV. In this study, we report for the first time the prevalence in Kuwait of non-polymorphic resistanceassociated mutations (RAMs) in patients under first-line antiretroviral therapy. Viral RNA was extracted from plasma samples of 64 treatment-naïve (untreated) and 64 treatment-experienced patients. The HIV-1 load was determined by real-time RT-PCR. The protease- and reverse transcriptase-encoding regions were analyzed by subtyping, and for drug resistance. The HIV-1 load at sampling in treatment-naïve patients ranged from $1.61 \mathrm{x}$ $10^{4}$ to $1.91 \times 10^{6} \mathrm{copies} / \mathrm{ml}$, whereas that in treatment-experienced patients ranged from $<20$ to $8.25 \times 10^{4} \mathrm{cop}$ ies/ml $(p<0.001)$. Ten different HIV-1 subtypes and recombinant forms were found with the predominance of CRF01_AE, B and C. Non-polymorphic mutations associated with resistance to antiretroviral drugs were detected in 8 treatment-naïve patients $(12.5 \%)$ and 11 treatment-experienced patients $(28.9 \% ; p=0.46)$. RAMs detected in treatment-naïve patients are known to be associated with resistance to non-nucleoside reverse transcriptase inhibitors (NNRTIs). Among treatment-experienced patients, five patients (13.1\%) had mutations associated with high-level resistance to nucleoside reverse transcriptase inhibitors (NRTIs), 4 patients (10.5\%) had mutations associated with resistance to NNRTIs, one patient (2.6\%) had resistance to both NRTIs and NNRTIs, and one patient (2.6\%) had resistance to both protease inhibitors (PIs) and NNRTIs. These results necessitate efforts to be made for reducing emergence of resistance-associated mutations in treated patients, and highlight the need for continuous monitoring of drug resistance patterns in Kuwait.
\end{abstract}

Keywords: HIV-1; genotyping; mutations; drug resistance; surveillance; Kuwait

\section{Introduction}

The goal of antiretroviral therapy (ART) is to maintain a durable suppression of HIV replication (Walensky et al.,

E-mail: wchehadeh@hsc.edu.kw; phone: +965-24636519.

Abbreviations: $3 \mathrm{TC}=$ Lamivudine; $\mathrm{ABC}=$ Abacavir; $\mathrm{ART}=$ antiretroviral; $\mathrm{ddI}=$ Didanosine; $\mathrm{EFV}=$ Efavirenz; $\mathrm{ETR}=$ Etravirine; FTC $=$ Emtricitabine; HIV = human immunodeficiency virus; INSTI = integrase strand transfer inhibitor; NNRTI = non-nucleoside reverse transcriptase inhibitor; NRTI $=$ nucleoside reverse transcriptase inhibitor; $\mathrm{NVP}=$ Nevirapine; $\mathrm{PI}=$ protease inhibitor; $\mathrm{RAM}=$ resistance-associated mutation; RPV = Rilpivirine; RT$\mathrm{PCR}=$ reverse transcription $-\mathrm{PCR} ; \mathrm{TDF}=$ Tenofovir; $\mathrm{WHO}=$ World Health Organization
2006). However, the emergence of drug resistance-associated mutations (RAMs) in the HIV pol gene is the main cause of therapy failure, which may lead to accelerated HIV progression and transmission of drugs-resistant strains to susceptible individuals (Little et al., 2002; Richman et al., 2009). In Kuwait, the prevalence of HIV-1 infection is low. A cumulative total of 252 Kuwaiti HIV cases had been reported till the end of 2013, with 30 to 50 new cases diagnosed annually (UNAIDS, 2014). In an attempt to prevent HIV transmission, pre-marital HIV screening became mandatory in Kuwait in 2009, and all expatriates seeking for residency permit are screened for HIV antibodies. Moreover, antiretroviral treatment is offered free of charge for all infected people. During the study period, the first-line therapeutic regimen in Kuwait 
was a NNRTI-based regimen. PI- and INSTI-based regimens were offered as second and third-line ART, respectively.

In a pilot study conducted on only 28 treatment-naïve Kuwaiti patients, a total of 10 different subtypes and recombinant forms were detected with predominance of subtypes B, C and CRF01_AE. In that study, two RAMs were detected, of which one was associated with low- to intermediate-level resistance to NNRTs (Chehadeh et al., 2015). However, drug resistance is more likely to occur wherever HIV therapy is applied, and continued therapy in the context of treatment failure will often lead to the emergence and accumulation of additional resistance mutations (Preston and Dougherty, 1996; Roberts et al., 1998). This applies particularly to drugs with low genetic barriers to resistance (Hirsch et al., 2008). Moreover, drug resistance is likely to occur when individuals do not adhere to anti-HIV drugs (Emamzadeh-Fard et al., 2012).

Antiretroviral treatment failure occurs in about $20 \%$ of people with HIV receiving first-line ART in low-resource settings. A second-line ART was offered to more than a halfmillion people in these settings in 2015, and the World Health Organization (WHO) projects that number will increase steadily over the next 10 years (Zhang et al., 2009; WHO, 2012; Haas and Keiser, 2016). To address concerns in Kuwait about the development of drug resistance during ART, the prevalence of RAMs in patients under first-line antiretroviral treatment was determined in this study, and compared to that in treatment-naïve patients.

\section{Materials and Methods}

Study population. From June 2011 through March 2016, plasma samples were collected from 64 treatment-naïv HIV-infected patients, and 64 patients under more than 6 months NNRTI-based regimen consisting of efavirenz (EFV) or nevirapine (NVP) with a combination of two NRTIs, lamivudine (3TC) or emtricitabine (FTC) + tenofovir (TDF) or abacavir (ABC). Patients with evidence of non-adherence to ART were excluded from this study. The ethical permission on this research study was granted by the Ethical Decision Committee of the Research Administration, Faculty of Medicine, Kuwait University, and by the Standing Committee for Coordination of Health and Medical Research, Ministry of Health.

HIV RNA concentrations. HIV-1 RNA concentrations in the plasma samples of recently diagnosed HIV-1 patients were determined by real-time PCR using the COBAS AmpliPrep/COBAS TaqMan HIV-1 test v2.0 (Roche Diagnostic Systems, Branchburg, NJ, USA), according to the manufacturer's instructions.

HIV-1 subtype classification. The isolation of viral RNA from clinical samples was performed using the automated MagNa Pure LC 2.0 system (Roche). Amplification and sequencing of 918-bp of the pol gene were performed using the TRUGENE HIV-1 Genotyp- ing Assay, on the OpenGene automated DNA Sequencing System (Siemens Healthcare Diagnostics, Norwood, MA, USA). When genotyping assay failed, in-house amplification and sequencing of a 1300-bp fragment of the pol gene by nested RT-PCR was carried out as described previously (WHO, 2010). The obtained nucleotide sequences consisting of the pol gene were searched against the NCBI GenBank database using Basic Local Alignment Search Tool (BLAST), and then aligned with all the HIV reference sequences available in the HIV sequence database (http://www.hiv. lanl.gov/) using ClustalW method in the Molecular Evolutionary Genetics Analysis (MEGA) software version 4.02 (Tamura et al., 2007). Phylogenetic trees were reconstructed using Bayesian and neighbor-joining methods, with evolutionary distances computed using the Kimura 2-parameter method. A bootstrap test with 1,000 replicates was used to estimate the confidence of branching patterns in the trees. The accession number of each HIV reference sequence was added to the taxon label in the phylogenetic tree. HIV-1 sequences resulting from this study were uploaded to GenBank database (Acc. Nos. HF937222 to HF937249, KM588925 to KM588956, and KX155586 to KX155647). The recombinant HIV-1 form was analyzed by performing boot scan analysis with a sliding window of $200 \mathrm{bp}$, incremental steps of 20 bases, and the Kimura two-parameter model using Simplot 3.5.1 software (Johns Hopkins University, Baltimore, USA). The boot scan analysis was performed first with only sequences from pure subtypes, then with all sequences including recombinant forms available in the HIV sequence database. All subtypes and CRFs (Circulating Recombinant Forms) were confirmed using the REGA HIV subtyping tool (http:// www.bioafrica.net/rega-genotype/html/subtypinghiv.html).

Drug resistance assessment. HIV-1 drug resistance was determined by sequencing the reverse transcriptase and protease regions on the HIV-1 pol gene. Prevalence of drug resistance was estimated using the World Health Organization (WHO) surveillance drugresistance mutations list (Bennett et al., 2009) and Stanford University genotypic resistance interpretation algorithm (http://hivdb. stanford.edu/) (Liu and Shafer, 2006).

Statistical analysis. The two-tailed Mann-Whitney $U$-test was used to assess the difference in HIV-1 load between two groups. A $2 \times 2$ contingency table was generated to compare different proportions using the Chi-square test and Fischer's exact test, as appropriate. The statistical analysis was performed using the IBM SPSS Statistics for Windows, version 23 (IBM Corp., Armonk, N.Y., USA).

\section{Results}

\section{Patient baseline characteristics}

During the study period, 64 patients were enrolled as newly diagnosed with HIV-1 infection, and 64 patients as previously diagnosed patients under antiretroviral therapy. The baseline characteristics of treatment-naïve and -expe- 
Table 1. Baseline characteristics of treatment-naïve HIV patients

\begin{tabular}{lll}
\hline & & n (\%) \\
\hline Gender & Male & $50(78.1)$ \\
& Female & $14(21.9)$ \\
Age median in year (range) & & $33.5(2$ days-70 years) \\
Nationality & Kuwaiti & $47(73.4)$ \\
& Non-Kuwaiti & $17(26.6)$ \\
Viral load (copies/ml) & $\leq 10^{4}$ & $0(0)$ \\
& $10^{4}-10^{5}$ & $36(56.25)$ \\
& $\geq 10^{5}$ & $28(43.75)$ \\
\hline
\end{tabular}

Table 2. Baseline characteristics of treatment-experienced HIV patients

\begin{tabular}{lll}
\hline & & $\mathbf{n}(\mathbf{\%})$ \\
\hline Gender & Male & $40(62.5)$ \\
& Female & $24(37.5)$ \\
Age median in years (range) & & $33.5(4$ months-67 years) \\
Nationality & Kuwaiti & $55(85.9)$ \\
& Non-Kuwaiti & $9(14.1)$ \\
Viral load (copies/ml) & $\leq 10^{4}$ & $45(70.3)$ \\
& $10^{4}-10^{5}$ & $19(29.7)$ \\
& $\geq 10^{5}$ & $0(0)$ \\
\hline
\end{tabular}

Table 3. HIV-1 subtypes in treatment-naïve and -experienced patients

\begin{tabular}{lccc}
\hline & $\begin{array}{c}\text { Treatment- } \\
\text { naïve } \\
\text { patients } \\
\mathbf{n}(\%)\end{array}$ & $\begin{array}{c}\text { Treatment- } \\
\text { experienced } \\
\text { patients } \\
\mathbf{n}(\%)\end{array}$ & Total n (\%) \\
\hline A & $5(7.8)$ & $2(5.3)$ & $7(6.9)$ \\
B & $13(20.3)$ & $5(13.1)$ & $18(17.6)$ \\
C & $17(26.6)$ & $8(21.1)$ & $25(24.5)$ \\
G & $0(0)$ & $1(2.6)$ & $1(0.98)$ \\
CRF01_AE & $19(29.7)$ & $16(42.1)$ & $35(34.3)$ \\
CRF02_AG & $5(7.8)$ & $5(13.1)$ & $10(9.8)$ \\
CRF32_06A1 & $1(1.6)$ & $0(0)$ & $1(0.98)$ \\
CRF35_AD & $2(3.1)$ & $1(2.6)$ & $3(2.9)$ \\
CRF50_A1D & $1(1.6)$ & $0(0)$ & $1(0.98)$ \\
A1, B & $1(1.6)$ & $0(0)$ & $1(0.98)$ \\
\hline Total & $\mathbf{6 4 ( 1 0 0 )}$ & $\mathbf{3 8 ( 1 0 0 )}$ & $\mathbf{1 0 2}(\mathbf{1 0 0})$ \\
\hline
\end{tabular}

rienced patients are given in Tables 1 and 2, respectively. Their age ranged from 2 days to 70 years, with a median age of 33.5 years. Most patients were male Kuwaiti. The median viral load at sampling in treatment-naïve patients $\left(1.08 \times 10^{5}\right.$ RNA copies/ml; range: $1.61 \times 10^{4}$ to $1.91 \times 10^{6}$ copies $/ \mathrm{ml}$ ) was significantly higher than that in treatment-experienced patients $\left(3.76 \times 10^{2} \mathrm{RNA}\right.$ copies/ml; range: $<20$ to $8.25 \times 10^{4}$ copies/ml; $p<0.001)$.

\section{Subtype distribution}

Complete sequence information was obtained for only 38 (59\%) treatment-experienced patients and for all 64 treatment-naïve patients. The samples that failed genotyping assay had a viral load $<100$ copies $/ \mathrm{ml}$. According to the sequence analysis of the pol gene, CRF01_AE was the most prevalent subtype (34.3\%), followed by subtype C (24.5\%) and subtype B (17.6\%) (Table 3). Assignment of HIV-1 subtype was confirmed by phylogenetic analysis (Fig. 1). Additional subtypes detected were subtype A (6.9\%) and subtype $\mathrm{G}(\sim 1 \%)$. Sixteen patients had recombinant form of HIV-1 different from CRF01_AE, of whom 10 had CRF02_AG, and 3 had CRF35_AD, as confirmed by bootscanning analysis (Table 3).

\section{Drug resistance profile}

A total of 8 treatment-naïve patients $(12.5 \%)$ and 11 treatment-experienced patients $(28.9 \%)$ had non-polymorphic mutations associated with resistance to antiretroviral drugs $(p=0.46$; Table 4$)$. Seven treatment-naïve patients (10.9\%) and 5 treatment-experienced patients (13.1\%) had a single RAM, while one treatment-naïve patient (1.6\%) and 6 treatment-experienced patients $(15.8 \%)$ had more than one RAM. Non-polymorphic RAMs detected in treatmentnaïve patients are known to confer resistance to NNRTIs; one RAM, K103N, associated with high-level resistance to nevirapine (NVP) and efavirenz (EFV), was detected in 4 treatment-naive patients (6.25\%). The A98G mutation associated with low-level resistance to EFV, etravirine (ETR) and rilpivirine (RPV), and intermediate resistance to NVP was detected in 5 treatment-naïve patients. Non-polymorphic mutations associated with resistance to NRTIs and PIs were not detected in treatment-naïve patients.

Among treatment-experienced patients, 5 patients (13.1\%) had mutations associated with resistance to NRTIs, 4 patients $(10.5 \%)$ had mutations associated with resistance to NNRTIs, one patient (2.6\%) had mutations associated with resistance to both NRTIs and NNRTIs, and one patient (2.6\%) had mutations associated with resistance to both PIs and NNRTIs. Among treatment-experienced patients with mutations associated with resistance to NRTIs, 5 (13.1\%) had the $\mathrm{M} 184 \mathrm{~V}$ mutation associated with high-level resistance to lamivudine (3TC) and emtricitabine (FTC), and low-level resistance to didanosine (ddI) and abacavir (ABC). Among treatment-experienced patients with mutations associated with resistance to NNRTIs, two patients had the K103N mutation; one patient had the K103N and Y181C mutations associated with high-level resistance to NVP and EFV, and intermediate resistance to ETR and RPV; one patient had the A98G and K101E mutations associated with high-level resistance to NVP, intermediate resistance to RPV, and low- 


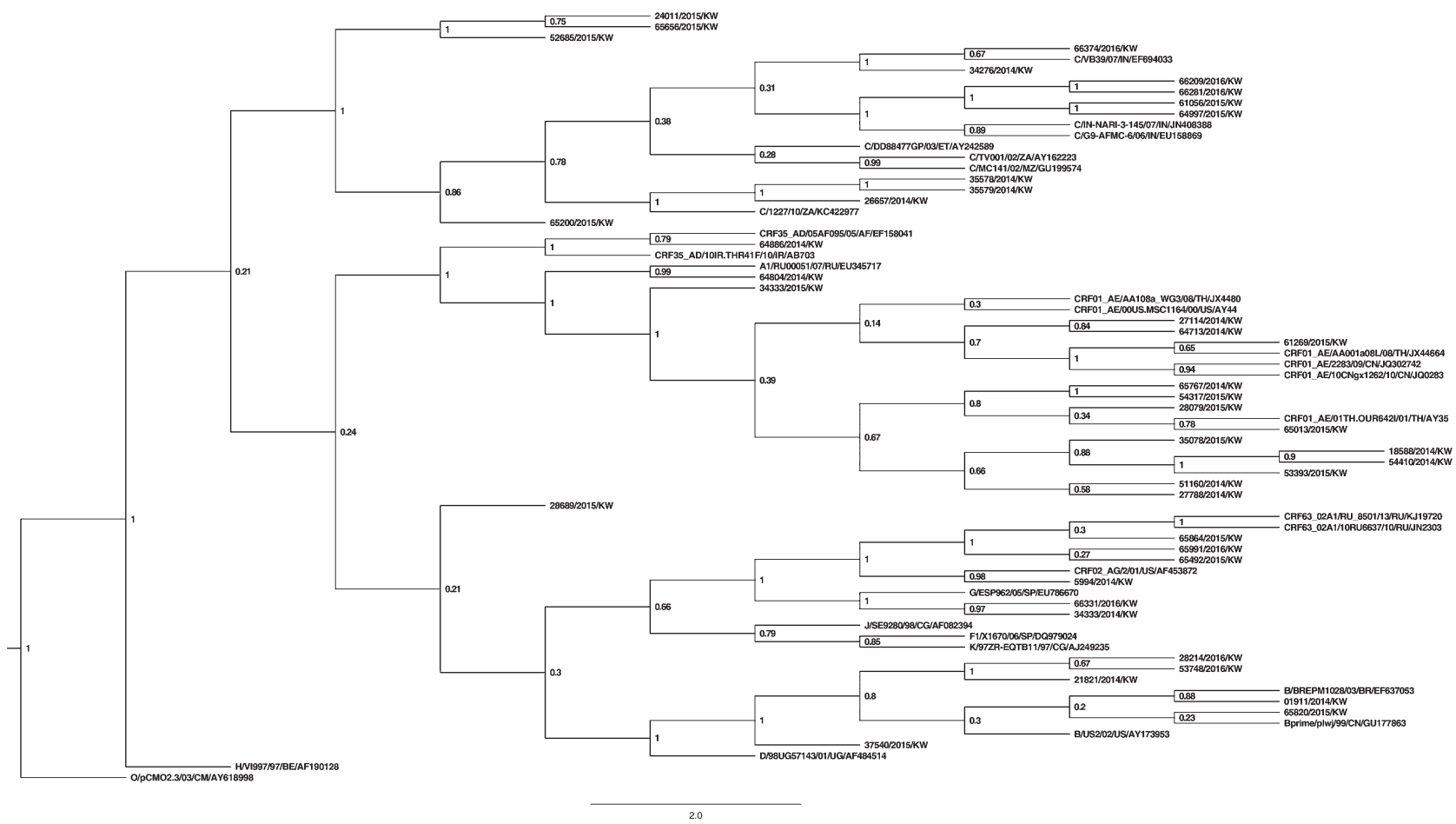

Fig. 1

Phylogenetic analysis of a partial fragment of the HIV pol gene

The posterior values of replicate trees, in which the associated taxa clustered together in the Bayesian method are shown next to the branches. The evolutionary distances are in the units of the number of base substitutions per site. Each HIV reference sequence is labeled with its corresponding subtype followed by strain's name, sampling year, two-letter country code, and GenBank Acc. No. For clarity of the figure, only sequences from some patients with pure HIV-1 subtype and patients with CRF01_AE subtype were included.

Table 4. Resistance-associated mutations (RAMs) in HIV-1 patients

\begin{tabular}{|c|c|c|c|c|}
\hline \multicolumn{5}{|c|}{ Treatment-naïve patients } \\
\hline RAM(s) & Resistance to & Resistance level & HIV-1 subtype & n (\%) \\
\hline A98G & NNRTI(s) & Potential low & CRF01_AE & $4(6.25)$ \\
\hline $\mathrm{K} 103 \mathrm{~N}$ & NNRTI(s) & High & $\begin{array}{l}\text { A, CRF35_AD, } \\
\text { CRF32_06A1 }\end{array}$ & $3(4.7)$ \\
\hline $\mathrm{A} 98 \mathrm{G}+\mathrm{K} 103 \mathrm{~N}$ & NNRTI(s) & High & CRF01_AE & $1(1.6)$ \\
\hline & & & & Total: 8 (12.5) \\
\hline \multicolumn{5}{|c|}{ Treatment-experienced patients } \\
\hline RAM(s) & Resistance to & Resistance level & HIV-1 subtype & n (\%) \\
\hline K70T & NRTI(s) & Potential low & $\mathrm{C}$ & $1(2.6)$ \\
\hline K103N & NNRTI(s) & High & A, CRF01_AE & $2(5.3)$ \\
\hline $\mathrm{M} 184 \mathrm{~V}$ & NRTI(s) & High & CRF01_AE & $2(5.3)$ \\
\hline $\mathrm{L} 10 \mathrm{~F}+\mathrm{V} 179 \mathrm{~T}$ & PI(s)+NNRTI(s) & Potential low & CRF02_AG & $1(2.6)$ \\
\hline $\mathrm{A} 98 \mathrm{G}+\mathrm{K} 101 \mathrm{E}$ & NNRTI(s) & High & CRF01_AE & $1(2.6)$ \\
\hline $\mathrm{M} 41 \mathrm{~L}+\mathrm{M} 184 \mathrm{~V}$ & $\operatorname{NRTI}(s)$ & High & B & $1(2.6)$ \\
\hline $\mathrm{K} 70 \mathrm{E}+\mathrm{M} 184 \mathrm{~V}$ & NRTI(s) & High & CRF01_AE & $1(2.6)$ \\
\hline $\mathrm{K} 103 \mathrm{~N}+\mathrm{Y} 181 \mathrm{C}$ & NNRTI(s) & High & CRF01_AE & $1(2.6)$ \\
\hline $\begin{array}{l}\text { M184V+K219Q+ } \\
\text { V108I+E138K+ } \\
\text { F227L+M230L }\end{array}$ & $\operatorname{NRTI}(s)+\operatorname{NNRTI}(s)$ & High & B & $1(2.6)$ \\
\hline & & & & Total: $11(28.9)$ \\
\hline
\end{tabular}


level resistance to EFV and ETR; one patient had the V179T mutation potentially associated with low-level resistance to all available NNRTIs. One patient with HIV-1 subtype B infection had multiple RAMs (M184V, K219Q, V108I, E138K, F227L and M230L) known to confer high-level resistance to 3TC, FTC, EFV, NVP and RPV, intermediate resistance to ETR, and low-level resistance to ABC and ddI.

The mutation profiles were consistent with treatment status, with the K103N and Y181C mutations identified in patients treated with EFV or NVP, and the M184V mutation found in patients treated with 3TC. However, in one patient on NNRTI-based regimen with no history of previous exposure to PIs, two RAMs were detected, L10F potentially conferring low-level resistance to the protease inhibitors, fosamprenavir/ritonavir (FPV/r), indinavir/r (IDV/r) and nelfinavir (NFV), and V179T potentially associated with low-level resistance to all available NNRTIs. All treatmentexperienced patients with high-level resistance to RTIs ( $n=9,23.7 \%$ ) had detectable plasma HIV-1 RNA level with median viral load of $4.69 \times 10^{3}$ RNA copies/ml (range, 2.85 $\mathrm{x} 10^{2}$ to $6.49 \times 10^{4}$ RNA copies $/ \mathrm{ml}$ ).

\section{Discussion}

In line with our previous observations, CRF01_AE, C and $\mathrm{B}$ were the most prevalent subtypes detected in Kuwait (Chehadeh et al., 2015). This agrees with other findings reported in the Gulf region concerning the circulation of pure subtypes A, B, C, and of recombinant forms such as CRF35_AD (Sarrami-Forooshani et al., 2006; Badreddine et al., 2007; Alzahrani, 2008; Jahanbakhsh et al., 2013; Baesi et al., 2014a). Of interest, around $10 \%$ of the patients had HIV-1 subtype CRF02_AG that is prevalent in West Africa and Russia with global prevalence of $\sim 5 \%$ (Taylor et al., 2008). Moreover, one treatment-naïve Kuwaiti patient had the subtype CRF32_06A1 that was described in Estonia (Adojaan et al., 2005).

In the group of treatment-naïve patients, $12.5 \%$ of patients had HIV-1 sequence mutations (A98G, K103N) that are known to be associated with reduced susceptibility to NNRTIs. A98G ia a non-polymorphic accessory mutation that reduces NVP susceptibility by $\sim 5$-fold and EFV susceptibility by $\sim 3$-fold (Shafer et al., 2001; Vingerhoets et al., 2010). In combination with mutations at positions 90,98 , 100, 106, 181 and 190, A98G mutation causes resistance to etravirine (Hirsch et al., 2008; Johnson et al., 2013). However, four patients $(6.25 \%)$ had $\mathrm{K} 103 \mathrm{~N}$, a non-polymorphic mutation that causes $\sim 50$-fold reduced susceptibility to NVP, and $\sim 20$-fold reduced susceptibility to EFV (Johnson et al., 2005; Shafer, 2006). In a neighbor country like Iran, the frequency of RAMs in treatment-naive patients to any class of antiretroviral drugs was $15 \%$, which included mutations to NRTIs (10\%), and NNRTIs (5\%) (Memarnejadian et al., 2015). In other countries with dominant Muslim population like Turkey, $10 \%$ of treatment-naive patients exhibited mutations associated with resistance to NRTIs (5.2\%), NNRTIs (3.1\%), and PIs (2.1\%) (Yalçınkaya and Köse, 2014).

In the group of treatment-experienced patients, $28.9 \%$ had mutations known to be associated with resistance to antiretroviral drugs. About half of them had more than one primary mutation, which may result in greater reductions in susceptibility and virologic response than do single mutations. $\mathrm{M} 184 \mathrm{~V}$ was the predominant mutation that is associated with high-level resistance to 3TC and FTC, and low-level resistance to ddI and ABC. However, M184V is not contraindication to continued treatment with 3TC or FTC because it increases susceptibility to zidovudine (AZT), tenofovir (TDF) and stavudine (d4T), and is associated with clinically significant reductions in HIV-1 replication (Kuritzkes et al., 1996). K103N was the second most common detected mutation; it is known to confer high-level resistance to the first-generation NNRTIs, EFV and NVP, as described above. The presence of $\mathrm{K} 103 \mathrm{~N}$ alone does not affect the response to second-generation NNRTIs, ETR and RPV; however the accumulation of several mutations will compromise their efficacy (Scherrer et al., 2009; Tudor-Williams et al., 2014). Y181C detected in one treatment-experienced patient is a non-polymorphic mutation selected in patients receiving NVP, ETR and RPV. It reduces susceptibility to NVP, ETR, RPV, and EFV by $>50$-fold, 5-fold, 3-fold, and 2-fold, respectively. Although Y181C itself reduces EFV susceptibility by only 2 -fold, it is associated with a reduced response to an EFV-containing regimen because viruses with this mutation often harbor additional minority variant NNRTI-resistance mutations (Shafer et al., 2001; Johnson et al., 2005). In addition to Y181C mutation, E138K and K101E detected in two different treatment-experienced patients are associated with 2- to 3-fold reduced susceptibility to RPV. They occur commonly in patients receiving rilpivirine. E138K and to a lesser extent K101E usually occur in combination with the NRTI-resistance mutation M184I, which alone does not reduce rilpivirine susceptibility. When M184I is combined with E138K or K101E, rilpivirine susceptibility is reduced about 7-fold and 4.5-fold, respectively (Hu and Kuritzkes, 2011; Xu et al., 2011; Kulkarni et al., 2012; Rimsky et al., 2012).

In patients receiving NNRTI-based regimen, the prevalence of mutations associated with resistance to NRTIs, NNRTIs and PIs, was $15.8 \%, 13.1 \%$ and $2.6 \%$, respectively. In Saudi Arabia, $41 \%$ of treatment-experienced patients were reported to have NRTI-resistance mutations, $16 \%$ to have NNRTI-resistance mutations, and 13\% to have PI-resistance mutations (Jamjoom et al., 2010). In Iran, the prevalence of NRTI-, NNRTI- and PI-resistance mutations was reported to be $\sim 50 \%, 29 \%$ and $6.5 \%$, respectively (Baesi et al., 2014b). Data from neighbor countries are actually too scarce to 
evidence sizable discrepancies between results. Our results highlight the necessity of continuous surveillance of drug resistance in patients, thereby reducing the likelihood of treatment regimen failure.

Acknowledgments. This work was supported by Kuwait University Research Administration Grant No. RX 01/10.

\section{References}

Adojaan M, Kivisild T, Männik A, Krispin T, Ustina V, Zilmer K, Liebert E, Jaroslavtsev N, Priimägi L, Tefanova V, Schmidt J, Krohn K, Villems R, Salminen M, Ustav M (2005): Predominance of a rare type of HIV-1 in Estonia. J. Acquir. Immune Defic. Syndr. 39, 598-605.

Alzahrani AJ (2008): Analysis of HIV subtypes and the phylogenetic tree in HIV-positive samples from Saudi Arabia. Saudi Med. J. 29, 1394-1396.

Badreddine S, Smith K, van Zyl H, Bodelle P, Yamaguchi J, Swanson P, Devare SG, Brennan CA (2007): Identification and characterization of HIV type 1 subtypes present in the Kingdom of Saudi Arabia: high level of genetic diversity found. AIDS Res. Hum. Retroviruses 23, 667-674. https:// doi.org/10.1089/aid.2007.0185

Baesi K, Moallemi S, Farrokhi M, Alinaghi SA, Truong HH (2014a): Subtype classification of Iranian HIV-1 sequences registered in the HIV databases, 2006-2013. PLoS One 9, e105098. https://doi.org/10.1371/journal.pone.0105098

Baesi K, Ravanshad M, Ghanbarisafari M, Saberfar E, Seyedalinaghi S, Volk JE (2014b): Antiretroviral drug resistance among antiretroviral-naïve and treatment experienced patients infected with HIV in Iran. J. Med. Virol. 86, 1093-1098. https://doi.org/10.1002/jmv.23898

Bennett DE, Camacho RJ, Otelea D, Kuritzkes DR, Fleury H, Kiuchi M, Heneine W, Kantor R, Jordan MR, Schapiro JM, Vandamme AM, Sandstrom P, Boucher CA, van de Vijner D, Rhee SY, Liu TF, Pillay D, Shafer RW (2009): Drug resistance mutations for surveillance of transmitted HIV-1 drug-resistance: 2009 update. PLoS One 4, e4724. https://doi.org/10.1371/journal.pone.0004724

Chehadeh W, Albaksami O, Altawalah H, Ahmad S, Madi N, John SE, Abraham PS, Al-Nakib W (2015): Phylogenetic analysis of HIV-1 subtypes and drug resistance profile among treatment-naïve people in Kuwait. J. Med. Virol. 87, 1521-1526. https://doi.org/10.1002/jmv.24212

Emamzadeh-Fard S, Fard SE, SeyedAlinaghi S, Paydary K (2012): Adherence to anti-retroviral therapy and its determinants in HIV/AIDS patients: a review. Infect. Disord. Drug Targets 12, 346-356. https://doi. org/10.2174/187152612804142251

Haas AD, Keiser O (2016): Raltegravir in second-line ART in resource-limited settings. Lancet HIV 3, e240-241. https://doi.org/10.1016/S2352-3018(16)30014-5

Hirsch MS, Gunthard HF, Schapiro JM, Brun-Vezinet F, Clotet B, Hammer SM, Johnson VA, Kuritzkes DR, Mellors JW, Pillay D, Yeni PG, Jacobsen DM, Richman DD (2008):
Antiretroviral drug resistance testing in adult HIV-1 infection: 2008 recommendations of an International AIDS Society-USA panel. Clin. Infect. Dis. 47, 266-285. https://doi.org/10.1086/589297

$\mathrm{Hu}$ Z, Kuritzkes DR (2011): Interaction of reverse transcriptase (RT) mutations conferring resistance to lamivudine and etravirine: effects on fitness and RT activity of human immunodeficiency virus type 1. J. Virol. 85, 11309-11314. https://doi.org/10.1128/JVI.05578-11

Jahanbakhsh F, Ibe S, Hattori J, Monavari SH, Matsuda M, Maejima M, Iwatani Y, Memarnejadian A, Keyvani H, Azadmanesh K, Sugiura W (2013): Molecular epidemiology of HIV type 1 infection in Iran: genomic evidence of CRF35_AD predominance and CRF01_AE infection among individuals associated with injection drug use. AIDS Res. Hum. Retroviruses 29, 198-203. https://doi.org/10.1089/ aid.2012.0186

Jamjoom GA, Azhar EI, Madani TA, Hindawi SI, Bakhsh HA, Damanhouri GA (2010): Genotype and antiretroviral drug resistance of human immunodeficiency virus-1 in Saudi Arabia. Saudi Med. J. 31, 987-992.

Johnson JA, Li JF, Morris L, Martinson N, Gray G, McIntyre J, Heneine W (2005): Emergence of drug-resistant HIV-1 after intrapartum administration of single dose nevirapine is substantially underestimated. J. Infect. Dis. 192, 16-23. https://doi.org/10.1086/430741

Johnson VA, Calvez V, Gunthard HF, Paredes R, Pillay D, Shafer RW, Wensing AM, Richman DD (2013): Update of the drug resistance mutations in HIV-1: March 2013. Top. Antivir. Med. 21, 6-14.

Kulkarni R, Babaoglu K, Lansdon EB, Rimsky L, Van Eygen V, Picchio G, Svarovskaia E, Miller MD, White KL (2012): The HIV-1 reverse transcriptase M184I mutation enhances the $\mathrm{E} 138 \mathrm{~K}$-associated resistance to rilpivirine and decreases viral fitness. J. AIDS 59, 47-54. https://doi. org/10.1097/QAI.0b013e31823aca74

Kuritzkes DR, Quinn JB, Benoit SL, Shugarts DL, Griffin A, Bakhtiari M, Poticha D, Eron JJ, Fallon MA, Rubin M (1996): Drug resistance and virologic response in NUCA 3001, a randomized trial of lamivudine (3TC) versus zidovudine (ZDV) versus ZDV plus 3TC in previously untreated patients. AIDS 10, 975-981. https://doi. org/10.1097/00002030-199610090-00007

Little SJ, Holte S, Routy JP, Daar ES, Markowitz M, Collier AC, Koup RA, Mellors JW, Connick E, Conway B, Kilby M, Wang L, Whitcomb JM, Hellmann NS, Richman DD (2002): Antiretroviral-drug resistance among patients recently infected with HIV. N. Engl. J. Med. 347, 385-394. https:// doi.org/10.1056/NEJMoa013552

Liu TF, Shafer RW (2006): Web Resources for HIV type 1 Genotypic-Resistance Test Interpretation. Clin. Infect. Dis. 42, 1608-1618. https://doi.org/10.1086/503914

Memarnejadian A, Menbari S, Mansouri SA, Sadeghi L, Vahabpour R, Aghasadeghi MR, Mostafavi E, Abdi M (2015): Transmitted drug resistance mutations in antiretroviralnaïve injection drug users with chronic HIV-1 infection in Iran. PLoS One 10, e0126955. https://doi.org/10.1371/ journal.pone.0126955 
Preston BD, Dougherty JP (1996): Mechanisms of retroviral mutation. Trends Microbiol. 4, 16-21. https://doi. org/10.1016/0966-842X(96)81500-9

Richman DD, Margolis DM, Delaney M, Greene WC, Hazuda D, Pomerantz RJ (2009): The challenge of finding a cure for HIV infection. Science 323, 1304-1307. https://doi. org/10.1126/science.1165706

Rimsky L, Vingerhoets J, Van Eygen V, Eron J, Clotet B, Hoogstoel A, Boven K, Picchio G (2012): Genotypic and phenotypic characterization of HIV-1 isolates obtained from patients on rilpivirine therapy experiencing virologic failure in the phase 3 ECHO and THRIVE studies: 48-week analysis. J. Acquir. Immune Defic. Syndr. 59, 39-46. https://doi. org/10.1097/QAI.0b013e31823df4da

Roberts JD, Bebenek K, Kunkel TA (1998): The accuracy of reverse transcriptase from HIV-1. Science 242, 1171-1173. https://doi.org/10.1126/science. 2460925

Sarrami-Forooshani R, Das SR, Sabahi F, Adeli A, Esmaeili R, Wahren B, Mohraz M, Haji-Abdolbaghi M, Rasoolinejad M, Jameel S, Mahboudi F (2006): Molecular analysis and phylogenetic characterization of HIV in Iran. J. Med. Virol. 78, 853-863. https://doi.org/10.1002/jmv.20634

Scherrer AU, Hasse B, von Wyl V, Yerly S, Böni J, Bürgisser P, Klimkait T, Bucher HC, Ledergerber B, Günthard HF (2009): Prevalence of etravirine mutations and impact on response to treatment in routine clinical care: the Swiss HIV Cohort Study (SHCS). HIV Med. 10, 647-656. https://doi.org/10.1111/j.1468-1293.2009.00756.x

Shafer RW (2006): Rationale and Uses of a Public HIV DrugResistance Database. J. Infect. Dis. 194 (Suppl. 1), S51-8. https://doi.org/10.1086/505356

Shafer RW, Dupnik K, Winters MA, Eshleman SH (2001): A Guide to HIV-1 Reverse Transcriptase and Protease Sequencing for Drug Resistance Studies. HIV Seq. Compend. 2001, 1-51.

Tamura K, Dudley J, Nei M, Kumar S (2007): MEGA4: Molecular Evolutionary Genetics Analysis (MEGA) software version 4.0. Mol. Biol. Evol. 24, 1596-1599. https://doi. org $/ 10.1093 / \mathrm{molbev} / \mathrm{msm} 092$

Taylor BS, Sobieszczyk ME, McCutchan FE, Hammer SM (2008): The challenge of HIV-1 subtype diversity. N. Engl. J. Med. 358, 1590-1602. https://doi.org/10.1056/NEIMra0706737

Tudor-Williams G, Cahn P, Chokephaibulkit K, Fourie J, Karatzios C, Dincq S, Opsomer M, Kakuda TN, Nijs S, Tambuyzer
L, Tomaka FL; PIANO study group (2014): Etravirine in treatment-experienced, HIV-1-infected children and adolescents: 48 -week safety, efficacy and resistance analysis of the phase II PIANO study. HIV Med. 15, 513-524. https://doi.org/10.1111/hiv.12141

UNAIDS. Global AIDS Response Progress Report (2014): Country Progress Report. State of Kuwait. Available at: http:// www.unaids.org/en/regionscountries/countries/kuwait/ Accessed October 22, 2014

Vingerhoets J, Tambuyzer L, Azijn H, Hoogstoel A, Nijs S, Peeters M, de Béthune MP, De Smedt G, Woodfall B, Picchio G (2010): Resistance profile of etravirine: combined analysis of baseline genotypic and phenotypic data from the randomized, controlled Phase III clinical studies. AIDS 24, 503. https://doi.org/10.1097/QAD.0b013e32833677ac

Wainberg MA, Zaharatos GJ, Brenner BG (2011): Development of antiretroviral drug resistance. N. Engl. J. Med. 365, 637-646. https://doi.org/10.1056/NEJMra1004180

Walensky RP, Paltiel AD, Losina E, Mercincavage LM, Schackman BR, Sax PE, Weinstein MC, Freedberg KA (2006): The survival benefits of AIDS treatment in the United States. J. Infect. Dis. 194, 11-19. https://doi.org/10.1086/505147

World Health Organization (WHO) (2010): WHO manual for HIV drug resistance testing using dried blood spot specimens. Available at: http://www.who.int/hiv/pub/drugresistance/ en/ Accessed October 22, 2014.

World Health Organization (WHO), WHO Res Net, including Jordan MR, Barcarolo J, Parkin N, de Oliveira T, Bertagnolio s (2012): WHO HIV drug resistance report. Geneva, Switzerland, WHO, 2012.

Xu HT, Asahchop EL, Oliveira M, Quashie PK, Quan Y, Brenner BG, Wainberg MA (2011): Compensation by the E138K mutation in HIV-1 reverse transcriptase for deficits in viral replication capacity and enzyme processivity associated with the M184I/V mutations. J. Virol. 85, 11300-11308. https://doi.org/10.1128/JVI.05584-11

Yalçinkaya T, Köse S (2014): Investigation of HIV-1 primary drug resistance mutations in antiretroviral therapy-naive cases. Mikrobiol. Bul. 48, 585-595. https://doi.org/10.5578/ $\underline{m b .8321}$

Zhang F, Dou Z, Ma Y, Zhao Y, Liu Z, Bulterys M, Chen RY (2009): Five year outcomes of the China National Free Antiretroviral Treatment Program. Ann. Intern. Med. 151, 241-251. https://doi.org/10.7326/0003-4819-1514-200908180-00006 